\title{
Improvement Research of Office Automation Achievements Analysis on the Computer Grade Examination in Universities of Jilin Province
}

\author{
Feifei Wang \\ Jilin HuaQiao University of Foreign Languages, No.3658.JingYue Street, ChangChun City,JinLin \\ Prov,China,130000
}

\begin{abstract}
Keywords: Improvement, Office Automation Achievements Analysis, Computer Grade Examination, Universities, Jilin Province
\end{abstract}

\begin{abstract}
By tracking the students in the study of university computer basic courses at different stages of the results, generate data analysis, in the "data" under the guidance of more targeted to find the problem, analyze the problem, solve the problem, promote the university computer basic teaching reform. The construction of the office automation achievements analysis provides a more accurate direction and a more scientific reference for the computer grade examination.
\end{abstract}

\section{Introduction}

With the continuous development of computer technology and computer application, the information society has continuously improved the demand for personnel training, and people have felt the profound influence of computer and information technology on the individual and society, and the basic education of computer in higher education is to a large extent determine the future of social students apply computer means and information technology to solve their own problems in the field of work capacity. In order to scientifically evaluate the quality of basic teaching of computer science in Jilin Province, Jilin Provincial Department of Education has reformed the "National College Student Computer Automation Examination (Jilin Kobo)" from 2013 onwards, and reformed the original written examination System application. Jilin Huaqiao Foreign Language Institute as one of the participating units of the reform, the Jilin Provincial Department of Education designated as the "National University Computer Automation Examination (Jilin test area)" test library construction units. In order to understand the actual situation of college students, more scientific for the examination, improve the quality of test library construction, and keep up with the development of computer teaching content, to enhance the teaching software version, to promote the province's university computer basic teaching reform, research and practice platform, through the scientific system to track, collect and analyze students in the university computer basic courses at different stages of the test results, generate data analysis, under the "data" under the guidance of more targeted to find the problem, analyze the problem, solve and to promote the reform of the university computer basic teaching of the university. At the same time, it provides a more accurate direction and scientific reference for the construction of the examination database of the National College Student Computer Automation Examination (Jilin Examination Area), so that the test version can adapt to the computer knowledge And the application of the province's computer basic teaching content of the update, to provide reference for the reform and reference.

\section{The Necessity of Computer Grade Examination Reform in Colleges and Universities in Jilin Province}

At present, the traditional theoretical and practical teaching content has been unable to meet the needs of market development, which also led to the test of students the ability of computer application standards cannot fully meet the development of computer technology and the actual needs of the employer, the application of computer application ability should be combined with the market practical needs, pay attention to "practical, applied." So, how to closely combine student employment and career needs, examine the practical application of computer skills and office skills? The traditional paper examination form and the question bank obviously has not adapted to the 
development of new computer technology, not scientific and objective test students in the office environment in the computer and office automation practical operation ability. Practice teaching content to follow the market of computer and office automation updates and changes in the reform and filling, narrowing and even eliminate the gap between the learned and used to do with the times, and market synchronization.

In order to make the computer grade test of college students in Jilin Province more adaptable to the development of computer technology and the pace of computer basic teaching reform in colleges and universities in Jilin Province, Jilin University Department of Education Examination Management Office organized a number of university experts and teaching front-line teachers to form a " National college students computer grade examination (Jilin examination area) reform and practice "research group, how to reform Jilin University students computer grade examination form and content. "Jilin Province, college students computer office automation examination reform and practice" topic is "Jilin Provincial Department of Education, college entrance examination management office" support, by the "Jilin province computer common teaching professional committee" lead, and joint Jilin Province, part of the university research " The National College Students Computer Level Examination (Jilin Pavilion) reform and practice "in the" computer office automation level examination "part of the sub-subject research, hope to develop more in line with the law of computer teaching, to meet the continuous development of computer technology and social needs of the test form and content, a common computer office automation practice application ability test platform. At the same time, to further promote the university computer basic teaching reform.

\section{Analysis of Office Automation Achievements}

Taking the school as the research and practice platform, we follow the process of learning the basic course of the college students' university in 2015 and collect the performance data. In order to compare and analyze the learning effect of the students, the data of the following analysis tables are " Admission test results "'" second test scores "and" final exam results ", the results of comparative analysis as follows.

Through the above data analysis can be found: At present, although the information technology education in primary and secondary schools has been gradually popular, many students have access to the University before the computer has a basic understanding and a certain application base, but most students are still relatively shallow knowledge or only interested in the content of a relatively good understanding and application, and master the computer knowledge fragmentation; office software in the actual work of how to apply, the specific solution to the office problem is not clear, in particular, excel spreadsheet software is at present, enterprises and institutions use one of the more software, and students of the software application base is almost zero, while in addition to office other than the office application software awareness is less, the computer knowledge in the work of the specific application is missing status.

\section{The Reform Direction of the Computer Grade Examination in Colleges and Universities in Jilin Province}

According to the Ministry of Education on the basic requirements of the computer curriculum requirements, the Jilin Provincial Department of Education on the computer grade examination requirements, the university's computer teaching reform and the actual needs of employers, the reform is mainly for Jilin Province, college students computer grade examination of the form and content of the reform, the original written examination of the form of reform for the machine test, to promote the machine (paperless) examination system, the unity of the province's test form; the preparation of computer office automation test outline, reform test content, the actual work needs of the future, focusing on student computer office automation practical application of the ability to develop new test standards; the establishment of computer office automation on the machine test questions library to achieve random computer subjects, automatic marking, to reflect the objective, 
fair and impartial principles ; The preparation of computer office automation practice teaching materials, published relevant research papers for the province, outside the other institutions of computer teaching to provide reference and reference to jointly promote the reform and development of computer teaching in colleges and universities. Reform first part of Jilin Province as a pilot unit, and then extended to other colleges and universities in Jilin Province.

The teaching content of modular, case-based, according to the weak links of students dynamic division of the contents of the module hours; the same time, in order to take care of different levels of students, each module based on teaching content to design basic cases, improve the case and comprehensive design case, so that individualized teaching.

The network as a platform to self-learning as the core, for students to build a learning resource library, network self-learning, teaching database and other services shared teaching platform to guide students to study autonomously and purposefully. At the same time, for students to update and expand some of the cutting-edge computer knowledge.

Follow up the development of computer hardware and software in a timely manner, update the version of the examination database, and constantly to the test questions to add a variety of questions; test questions should highlight the ability to understand the practical application of practical skills, the comprehensive use of capacity. In short, the construction of test questions library should reflect the new, refined, full and applicable.

\section{Suggestions on the Computer Grade Examination Reform in Universities of Jilin Province}

Chinese college office automation system since its inception, in improving the efficiency of administrative office and the quality of work has achieved some success. But at this stage of the university office automation system is also concerned about the content is too single, click rate is not high, user participation is not strong and so on. Office automation system involves the various functional departments of colleges and universities, involving government, administration, individual and other fields, involving computer technology, network technology, management engineering disciplines, so we have to design and develop a suitable for the actual situation of our university office system. Here the author only from the management level raised four points on the construction of our university office automation system views.

An important reason for the construction of office automation system in our country is the idea of management personnel. On the one hand, some of them are bound by the original office style, accustomed to the traditional office, rather than the use of office automation system to work; the other hand, now managers for our university office automation system awareness not enough. Only to understand it as a news release of the electronic platform, but did not realize that the real perfect office automation system should be achieved, including government management, financial management, personal assistant, including a variety of functions. And these functions is precisely the office automation system is the most important and indispensable part. To change this situation, I believe that from the following two aspects: (a) reform and improve the management system this is the fundamental solution to the problem. Reform the management system, make it into a standardized track; change the traditional work mode let it meet the requirements of office automation. Only in this way our university office automation system can give full play to its high efficiency, standardization, accuracy of the advantages.

Renewing Ideas and Enhancing Consciousness to enable college administrators to understand and fully understand the office automation system, they must use various channels to promote and educate them in order to change their minds. Only to improve people's office automation awareness, and gradually used to use office automation system. This is possible to speed up the pace of office automation. This requires a certain amount of investment and time, but also need the unit leadership, management cooperation and efforts. Second, improve the quality of personnel, and enhance the technical security at this stage, the office automation system is not high another reason is the quality of university management and technical support. On the one hand, the management staff because of the computer operating capacity is not high, resulting in not proficient use; the other hand, the office automation system technical support was not in place, so that the emergence of the problem. In 
view of the above two aspects, I believe: (A) vigorously improve the quality of university managers only when the system users to master a variety of modern office equipment, it is possible to improve office efficiency. As a result, the university management staff should continue to improve operational skills, so that they can skillfully use the office automation system. (B) Make efforts to enhance the system technical support office system professional construction staff should be used in a variety of technical measures to improve the reliability of equipment to ensure long-term stable operation of the office system. To eliminate some old leadership, old people "computer equipment unreliable" old ideas.

Now, in the process of running our office system, the various functional departments are not really involved in the construction of the system. In terms of the design of the system itself, it should be in the early stages of functional design and each department can only be fully demand analysis, given a certain degree of autonomy, so that they have more opportunities to participate. Fourth, improve the use of efficiency at present, Chinese university office automation system, although already have a certain basis, but the use of efficiency is not very high, there is still a small click rate, browsing timeliness is not enough. How to better use, play the function of the existing system has become a topic of concern. I believe that to improve the efficiency of the use of office automation system in China, from the following two aspects: (A) the release of the message should be for different users, whether leadership or general management, can have a certain system Message source. Only in this way will we attract attention to the system. Naturally, the click rate also increased. (B)It has been, various versions of our college office automation system are envisaged a lot of features, but the real use of the function is not much. Therefore, the author believes that on the one hand, we should be for the actual needs of managers to re-develop a really useful subsystem; the other hand, in the design of system function modules, try to "build one, run one, develop one, consolidate one to point with the surface, follow the side edge with edge benefit, and gradually improve the "principle, and finally the formation of a complete, reasonable and efficient university office automation system.

\section{Conclusion}

"Jilin Province, college students computer office automation examination reform" will reform the past paper-based, test-oriented and the actual operation of the test phase out of the test content and form, research and development in line with the basic computer teaching law to meet the application of talent to cultivate the requirements of the computer office automation test content, to build a scientific computer office automation on the machine test system platform, highlighting the "objectivity, impartiality, practicality, practicality" for the Jilin University college students in the computer office automation practical application ability to provide a unified, reasonable and accurate evaluation criteria.

\section{Acknowledgment}

This paper is a stage achievement of the key research on the reform of the higher education in jilin province. Project Name: Improvement Research of Office Automation Achievements Analysis on the Computer Grade Examination in Universities of Jilin Province

\section{References}

[1] Huifang Zhou: China New Communication, Vol. 6 (2004) No 53, p.25-26

[2] Hongli Zhang: Computer Education, Vol. 12 (2005) No 27, p.74-76

[3] Qin Guo: Electronic Production, Vol. 1 (2006) No 33, p.11-14

[4] Jieming Liu: Computer Knowledge and Technology, Vol. 3 (2007) No33, p.121-124

[5] Jia Xinzhang, Li Jingyuan. Electronic Production, Vol. 6 (2014) No 53, p.25-26 